\title{
Isolation of Cellulose from Wheat Straw Using Alkaline Hydrogen Peroxide and Acidified Sodium Chlorite Treatments: Comparison of Yield and Properties
}

\author{
Umair Qasim (D), ${ }^{1}$ Zulfiqar Ali, ${ }^{1}$ Muhammad Shahid Nazir, ${ }^{2}$ Sadaf Ul Hassan, ${ }^{2}$ \\ Sikander Rafiq $\mathbb{D}^{3}{ }^{3}$ Farrukh Jamil $\mathbb{D}^{1},{ }^{1}$ Ala'a H. Al-Muhtaseb, ${ }^{4}$ Muzaffar Ali, ${ }^{1}$ \\ Muhammad Bilal Khan Niazi $\mathbb{D}^{5},{ }^{5}$ Nasir M. Ahmad $\mathbb{D}^{6},{ }^{6}$ Sami Ullah $\mathbb{D D}^{7}$, Ahmad Mukhtar, \\ and Sidra Saqib ${ }^{1}$ \\ ${ }^{1}$ Department of Chemical Engineering, COMSATS University Islamabad, Lahore Campus, Islamabad, Pakistan \\ ${ }^{2}$ Department of Chemistry, COMSATS University Islamabad, Lahore Campus, Islamabad, Pakistan \\ ${ }^{3}$ Department of Chemical, Polymer and Composite Materials Engineering, University of Engineering and Technology, Lahore, \\ New Campus, Pakistan \\ ${ }^{4}$ Department of Petroleum and Chemical Engineering, College of Engineering, Sultan Qaboos University, Muscat, Oman \\ ${ }^{5}$ School of Chemical and Materials Engineering, National University of Sciences and Technology, Islamabad 44000, Pakistan \\ ${ }^{6}$ Polymer Research Lab, School of Chemical and Materials Engineering, National University of Sciences and Technology, \\ Islamabad 44000, Pakistan \\ ${ }^{7}$ Department of Chemistry, College of Science, King Khalid University, Abha 61413, Saudi Arabia \\ ${ }^{8}$ Department of Chemical Engineering, Universiti Teknologi PETRONAS (UTP), Seri Iskandar, Perak 32610, Malaysia
}

Correspondence should be addressed to Sikander Rafiq; sikanderafiq@gmail.com and Farrukh Jamil; fjamil@cuilahore.edu.pk

Received 5 November 2019; Revised 7 January 2020; Accepted 16 January 2020; Published 25 February 2020

Academic Editor: Alexandra Muñoz-Bonilla

Copyright ( 2020 Umair Qasim et al. This is an open access article distributed under the Creative Commons Attribution License, which permits unrestricted use, distribution, and reproduction in any medium, provided the original work is properly cited.

Environmental concerns due to excessive use of synthetic or petroleum-based materials have encouraged scientists to develop novel, sustainable, and multifunctional material using abundant lignocellulosic biomass. In this work, a study was conducted on the isolation of cellulose from wheat straw using two different methods: acidified sodium chlorite and alkaline hydrogen peroxide. A comparative study was carried out based on the yield and properties of extracted cellulose. The final product (after treatments) was characterized by Fourier transform infrared spectroscopy (FT-IR), X-ray diffraction (XRD), and thermogravimetric analysis (TGA) for the identification of properties. Both the treatments isolated pure white color cellulose. However, the yield of cellulose isolated through acidified sodium chlorite treatment (81.4\%) was higher than alkaline hydrogen peroxide treatment (79\%). Moreover, no huge difference was observed in the crystallinity and thermal properties of extracted cellulose.

\section{Introduction}

Excessive use and reliance on nonsustainable materials (synthetic or petroleum based) has led to ecological and economic crisis around the world. It leads researchers to find potential alternative that should be sustainable materials derived from renewable sources, especially lignocellulosic biomasses [1]. The utilization of products developed by using lignocellulosic biomass has numerous advantages over those made from petroleum fractions such as renewability, biodegradability, cost and energy effectiveness, and environmental friendly nature [2].

Among various biomass types, wheat straw (Triticum aestivum) is one of the most preferable biomass in the world because of its availability around the year. Pakistan is rich in the production of wheat. During 2017-18, wheat crop was cultivated on the area of 8,743 thousand hectares and 25.492 million tons of wheat was produced (Pakistan Bureau of 
Statistics). Thus, very small amount of wheat crop's waste is used for livestock, and mostly it is utilized for burning purpose, resulting environmental issues. Moreover, by considering all these factors, wheat straw can be considered as biomaterial for many domestic and industrial applications.

The amount of cellulose, hemicellulose, and lignin in wheat straw is $33-45 \%, 19-32 \%$, and $8-16 \%$, respectively [3]. Owing to the amount of cellulose content wheat straw contains, it can be used to isolate cellulose from noncellulosic components (hemicellulose and lignin). Cellulose is the most abundant biopolymer in the biosphere, consisting of glucose monomer units, connected via $\beta-1,4$ glycosidic linkages [4]. The interest in cellulose is due to its versatile properties like biocompatibility, renewability, biodegradability, and nontoxicity. Moreover, the conversion of cellulose into cellulose nanoparticles further enhanced its utilization because of increased specific surface area and aspect ratio and enhanced thermomechanical properties. These properties make cellulose nanoparticles one of the most attractive and innovative particles for novel applications ranging from cellulosic composites, filtration media, paints, packaging, biomedical, and adsorbent products [5]. List of applications of cellulose is given in Table 1.

The purpose of this work is to investigate and compare the yield and physicochemical properties of cellulose isolated from wheat straw using two different modified chemical treatments: acidified sodium chlorite (ASC) and alkaline hydrogen peroxide (AHP). FT-IR, SEM, XRD, and TGA were used for the identification and comparison of isolated cellulose via two different methods.

\section{Materials and Methods}

2.1. Materials. Wheat (Triticum aestivum) crop's waste commonly named as wheat straw (WS) used in this work was obtained from Shalimar store, a local market in Lahore, Pakistan. WS was first dewaxed using ethanol in a ratio $(0.1 \% \mathrm{w} / \mathrm{v}$, biomass/ethanol; $1: 10 \mathrm{~g} / \mathrm{mL})$ for 6 hours. Then, dewaxed wheat straw (DWS) was thoroughly washed with excessive water to discard unwanted particles and dried to a moisture content less than 10\% (ASTM D4442-16). Sodium chlorite $\left(\mathrm{NaClO}_{2}\right)$ of technical grade $(80 \%)$ was purchased from UNI-CHEM chemical reagents. Ethanol $\left(\mathrm{C}_{2} \mathrm{H}_{5} \mathrm{OH}\right)$, acetic acid $\left(\mathrm{CH}_{3} \mathrm{COOH}\right)$ of analytical grade, sodium hydroxide $(\mathrm{NaOH})$, and hydrogen peroxide $\left(\mathrm{H}_{2} \mathrm{O}_{2}\right)$ were purchased from Sigma Aldrich.

\subsection{Methods}

2.2.1. Isolation of Cellulose through Acidified Sodium Chlorite (ASC) Treatment. $2.5 \mathrm{~g}$ of DWS was dispersed in $80 \mathrm{~mL}$ hot water $\left(80^{\circ} \mathrm{C}\right)$. Suspension was then bleached by adding buffer of acetic acid $(0.5 \mathrm{~mL})$ and sodium chlorite $(1 \mathrm{~g})$ at reflux (oil bath at $80^{\circ} \mathrm{C}$ ) for 4 hours. The bleaching step was repeated four times. After the treatment, residue (holocellulose) was sieved and washed with excessive distilled water followed by oven drying at $75^{\circ} \mathrm{C}$ for 24 hours. Following bleaching treatment, the residue (holocellulose) was treated with $17.5 \%$ by weight of sodium hydroxide $(\mathrm{NaOH})$ solution $\left(100 \mathrm{~cm}^{3}\right)$ at room temperature for 30 minutes. Alkali $(\mathrm{NaOH})$ treatment was performed twice. The residue $\left(\mathrm{DWS}_{\mathrm{ASC}}\right)$ was filtered and then washed with excessive distilled water until neutral $\mathrm{pH}$. The residue $\left(\mathrm{DWS}_{\mathrm{ASC}}\right)$ was oven dried at $75^{\circ} \mathrm{C}$ before further use.

\subsubsection{Isolation of Cellulose through Alkaline Hydrogen} Peroxide (AHP) Treatment. AHP solution was prepared by mixing $1 \%$ alkaline solution $\left(1 \% ; \mathrm{NaOH} / \mathrm{H}_{2} \mathrm{O} ; 1 \mathrm{~g} / 100 \mathrm{~mL}\right)$ into $20 \%$ hydrogen peroxide solution $\left(20 \% ; \mathrm{H}_{2} \mathrm{O}_{2} / \mathrm{H}_{2} \mathrm{O}\right.$; $33.36 \mathrm{~g} / 166.7 \mathrm{~mL}$ ). $2.5 \mathrm{~g}$ of DWS was dispersed in $30 \mathrm{~mL}$ solution of alkaline hydrogen peroxide (AHP) in a stainless steel digester at $121^{\circ} \mathrm{C}$ for 35 minutes. After the particular time, the residue, $\mathrm{DWS}_{\mathrm{AHP}}$ (white color), was washed thoroughly with distilled water until it became free from chemicals and reached neutral $\mathrm{pH}$. The residue was then filtered, followed by oven drying at $75^{\circ} \mathrm{C}$ for further use.

2.3. Characterization. American Society for Testing Materials (ASTM) standards were used to identify the chemical composition of untreated and treated fibers. The content of $\alpha$-cellulose, lignin, and holocellulose were estimated using ASTM D1103-55T, ASTM D1106-56, and ASTM D1104-56, respectively. The standard deviation was calculated by conducting repeatedly experiments for each sample. The contents were calculated as follows:

$$
\begin{aligned}
\alpha-\text { cellulose }(\%) & =\frac{\text { weight of oven }- \text { dried } \alpha-\text { cellulose residue }}{W \times P}, \\
\text { hemicellulose }(\%) & =\left(\left[\frac{\text { weight of oven }- \text { dried holocellulose residue }}{W \times P}\right]\right) \times 100-A, \\
\text { lignin }(\%) & =\frac{\text { weight of oven }- \text { dried lignin residue }}{W \times P} \times 100,
\end{aligned}
$$

where $W=$ weight of the original oven dry sample and $P=$ proportion of moisture-free content.
The surface morphology of the cellulose obtained after two different treatments (alkaline hydrogen peroxide and acidified sodium chlorite treatment) was observed using a 
TABLe 1: Applications of cellulose particles.

\begin{tabular}{|c|c|c|}
\hline Area & Applications & Reference \\
\hline Rheology modifiers & $\begin{array}{l}\text { Rheological properties of various media (polymer melts, liquids, and particle mixtures) can be altered by } \\
\text { the use of cellulose which may be used in many applications such as coatings, paints, adhesives, drugs, } \\
\text { cement, food, and cosmetics }\end{array}$ & [6] \\
\hline $\begin{array}{l}\text { Reinforcement } \\
\text { (filler) }\end{array}$ & $\begin{array}{c}\text { Used as reinforcement in polymer matrix, it can improve mechanical properties of composites } \\
\text { (filler + matrix) which may be used to develop flexible, durable, lightweight, and transparent films for } \\
\text { structural and packaging applications }\end{array}$ & [7] \\
\hline Barrier films & $\begin{array}{c}\text { Modified cellulose polymer composites have shown attractive barrier properties with potential use in } \\
\text { batteries, packaging applications, and selective filtration }\end{array}$ & {$[8-11]$} \\
\hline Foams & $\begin{array}{l}\text { Foams made using cellulose nanoparticles are highly porous and can be used in lightweight packaging, } \\
\text { core-skin structure, and thermal and vibrational insulation }\end{array}$ & [7] \\
\hline Hybrid composites & $\begin{array}{l}\text { Cellulose could incorporate with inorganic nanoparticles to be reinforced in polymer matrix for } \\
\text { applications such as biosensors, catalysis, filters, drug delivery, and antimicrobial applications }\end{array}$ & {$[10,11]$} \\
\hline
\end{tabular}

variable pressure scanning electron microscope (TESCAN Vega LMU). Both the samples were gold coated before testing. The launching voltage of the microscope was $8.0 \mathrm{kV}$.

Chemical functional group analysis of DWS, DWS $\mathrm{ASC}_{\text {, }}$ and $\mathrm{DWS}_{\mathrm{AHP}}$ was performed using Fourier Transmission Nicolet 6700 . The FT-IR spectra were obtained at $4 \mathrm{~cm}^{-1}$ resolution in the standard wavelength range of 4000 to $450 \mathrm{~cm}^{-1}$. An X-ray diffractometer was used to evaluate the phase behavior of raw and treated wheat straw. Instrument conditions were set at $1.540 \AA$ wavelength ( $\mathrm{CuK} \alpha$ radiation), with a scan speed of $2^{\circ}$ per second and a $2 \theta$ range of $2-80^{\circ}$.

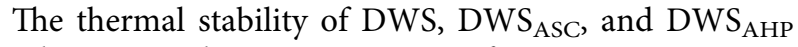
was characterized using TGA Q500 from TA Instruments Inc. (DE, USA). The sample size of each measurement was maintained at $2 \mathrm{mg}$. The TGA was performed under nitrogen environment with a clearance flow rate of $60 \mathrm{~mL} / \mathrm{min}$, and it was heated from $30^{\circ} \mathrm{C}$ to $500^{\circ} \mathrm{C}$ at $10^{\circ} \mathrm{C} / \mathrm{min}$ scanning rate according to ASTM E1131.

\section{Results and Discussion}

3.1. Chemical Composition of DWS. The chemical composition of raw material (DWS) was altered after the following treatments $\left(\mathrm{DWS}_{\mathrm{ASC}}\right.$ and $\left.\mathrm{DWS}_{\mathrm{AHP}}\right)$. In comparison with treated fibers, raw wheat straw fibers (DWS) have high percentage of hemicellulose and lignin with low percentage of cellulose as compared to treated fibers. The content of $\alpha$-cellulose increased from $44 \pm 0.5 \%$ to $81.4 \pm 1.5 \%$ by using acidified sodium chlorite treatment. Similarly, hemicellulose content decreased from $36 \pm 0.5 \%$ to $13 \pm 1 \%$ while lignin content decreased from $17 \pm 2 \%$ to $6 \pm 0.5 \%$. These results are similar to the results published before [12]. On the contrary, after alkaline hydrogen peroxide treatment, $\alpha$-cellulose content increased from $44 \pm 0.5 \%$ to $79 \pm 1.0 \%$, whereas, hemicellulose and lignin content decreased from $36 \pm 0.5 \%$ to $14 \pm 1 \%$ and $17 \pm 2 \%$ to $8 \pm 0.5 \%$, respectively. The ash content of raw wheat straw measured using ASTM (D2866) was $7.2 \pm 0.05$ which was in the range of results reported earlier [13-15].

3.2. FT-IR Spectrum of DWS, DWS $S_{A S C}$, and $D W S_{A H P}$. FT-IR was carried out to analyze the presence of the functional group on untreated wheat straw (DWS) and

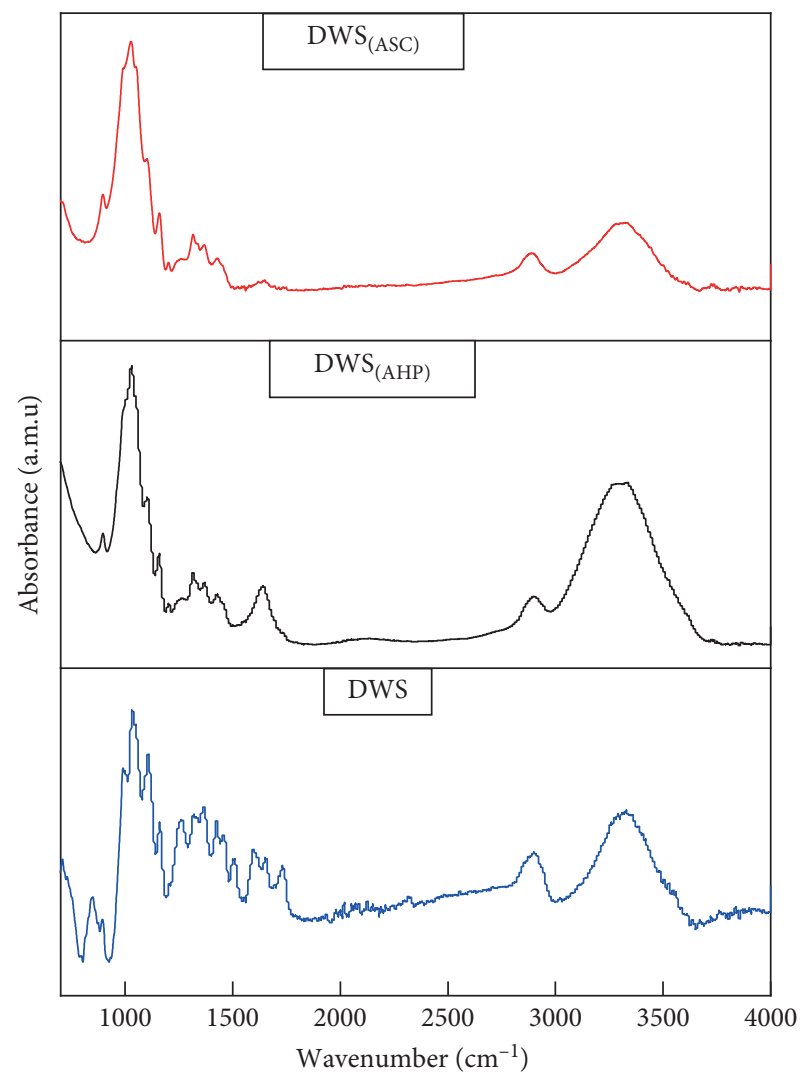

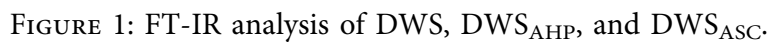

treated wheat straw $\left(\mathrm{DWS}_{\mathrm{ASC}}\right.$ and $\mathrm{DWS}_{\mathrm{AHP}}$ ) (Figure 1). The aim of this characterization is to identify the presence of cellulose, hemicellulose, and lignin before and after the particular treatment. All three samples presented wavelengths in the range $700-1800 \mathrm{~cm}^{-1}$ and $2700-3500 \mathrm{~cm}^{-1}$; however, specific peaks for each sample differentiate them. In the case of DWS, the absorption peaks at $3400 \mathrm{~cm}^{-1}$ and $2900 \mathrm{~cm}^{-1}$ represent $-\mathrm{OH}$ group and $\mathrm{C}-\mathrm{H}$ symmetric stretching vibrations, respectively. Similarly, peaks present at $1735 \mathrm{~cm}^{-1}$ and $1248 \mathrm{~cm}^{-1}$ are attributed to a waxy $\mathrm{C}=\mathrm{O}$ acetyl group of hemicellulose and $\mathrm{C}-\mathrm{O}-\mathrm{C}$ of aryl-alkyl-ether in lignin, respectively [16]. Moreover, the peaks at $1430 \mathrm{~cm}^{-1}, 1300 \mathrm{~cm}^{-1}$, and $1100 \mathrm{~cm}^{-1}$ in DWS showed the 
bending vibration of $-\mathrm{CH}_{2}, \mathrm{C}-\mathrm{H}$, and $\mathrm{C}-\mathrm{O}$ of cellulose in DWS spectra. While in the case of DWS $\mathrm{DSC}_{\mathrm{ASC}}$ and $\mathrm{DWS}_{\mathrm{AHP}}$, the peaks at $1644 \mathrm{~cm}^{-1}$ and $895 \mathrm{~cm}^{-1}$ represent the-OH bending of absorbed water and asymmetric out of plane ring stretching in cellulose, respectively. The absence of $1735 \mathrm{~cm}^{-1}$ and $1248 \mathrm{~cm}^{-1}$ peaks further confirms the removal of lignin and hemicellulose after the following treatments. The FT-IR spectra of cellulose reported earlier are well matched with current work that further confirms the removal of lignin and hemicellulose from DWS $[17,18]$.

3.3. XRD Diffractogram of DWS, $D W S_{A S C}$, and $D W S_{A H P}$. $\mathrm{XRD}$ diffractogram of DWS, $\mathrm{DWS}_{\mathrm{ASC}}$, and $\mathrm{DWS}_{\mathrm{AHP}}$ is shown in Figure 2. DWS fibers are combination of lignin and hemicellulose (amorphous region) and cellulose (crystalline region). After the treatments, the treated fibers, $\mathrm{DWS}_{\mathrm{ASC}}$ and $\mathrm{DWS}_{\mathrm{AHP}}$, showed the peak of high intensity at $22.5^{\circ}$. The peaks arise $\left(22.5^{\circ}\right)$ due to the fact that there is no doublet in the intensity of the main peak. This high-intensity peak defined the crystallinity of the substance. The high-intensity peak at $2 \theta=22.5^{\circ}$ is an indication of cellulose I polymorph which showed that the two procedures did not affect the crystal polymorphism of cellulose. Higher crystallinity is due to efficient removal of noncellulosic components. Crystallinity increases from $53.92 \%$ for DWS to $66.60 \%$ for $\mathrm{DWS}_{\mathrm{ASC}}$ and to $66.87 \%$ for DWS ${ }_{\text {AHP }}$. High-intensity peak (at $2 \theta=22.5^{\circ}$ ) of DWS $\mathrm{ASC}_{\mathrm{A}}$ and DWS $\mathrm{AHP}$ (extracted cellulose) is corresponding to the crystallographic plane (002), parallel to the results reported before $[19,20]$.

3.4. TGA Analyses of DWS, DWS $S_{A S C}$, and $D W S_{A H P}$. Thermal gravimetric measurement analysis was used to evaluate the thermal stability of DWS, cellulose extracted from DWS after the treatments (Figure 3). Because of the differences in the chemical structures among cellulose, hemicellulose and lignin, they are expected to decompose at different temperatures. The results of thermal analysis showed the deterioration of DWS in three stages started at $180^{\circ} \mathrm{C}$, then the second stage: $254^{\circ} \mathrm{C}$ and peaked at the third stage: $304^{\circ} \mathrm{C}$. The first stage is due to the degradation of hemicellulose and cellulose and the second is due to interference or overlapping between cellulose and lignin. The degradation of cellulose from ASC treated DWS was observed at $310^{\circ} \mathrm{C}$, and the decomposition temperature was $385^{\circ} \mathrm{C}$. Moreover, the cellulose obtained after AHP treatment on DWS starts degradation at $304^{\circ} \mathrm{C}$ and decomposed at $360^{\circ} \mathrm{C}$. It can be seen that chemical treatment increased both the starting and decomposition temperatures, which represented an increase in thermal stability. This can be attributed to the removal of noncellulosic substances (lignin and hemicelluloses) and a high degree of structural arrangement obtained after treatments [21, 22].

3.5. SEM Analysis of Cellulose. Figure 4 shows the micromorphology of extracted cellulose from wheat straw using two different treatments. Cellulose obtained after alkaline hydrogen peroxide treatment is irregular in shape, showing

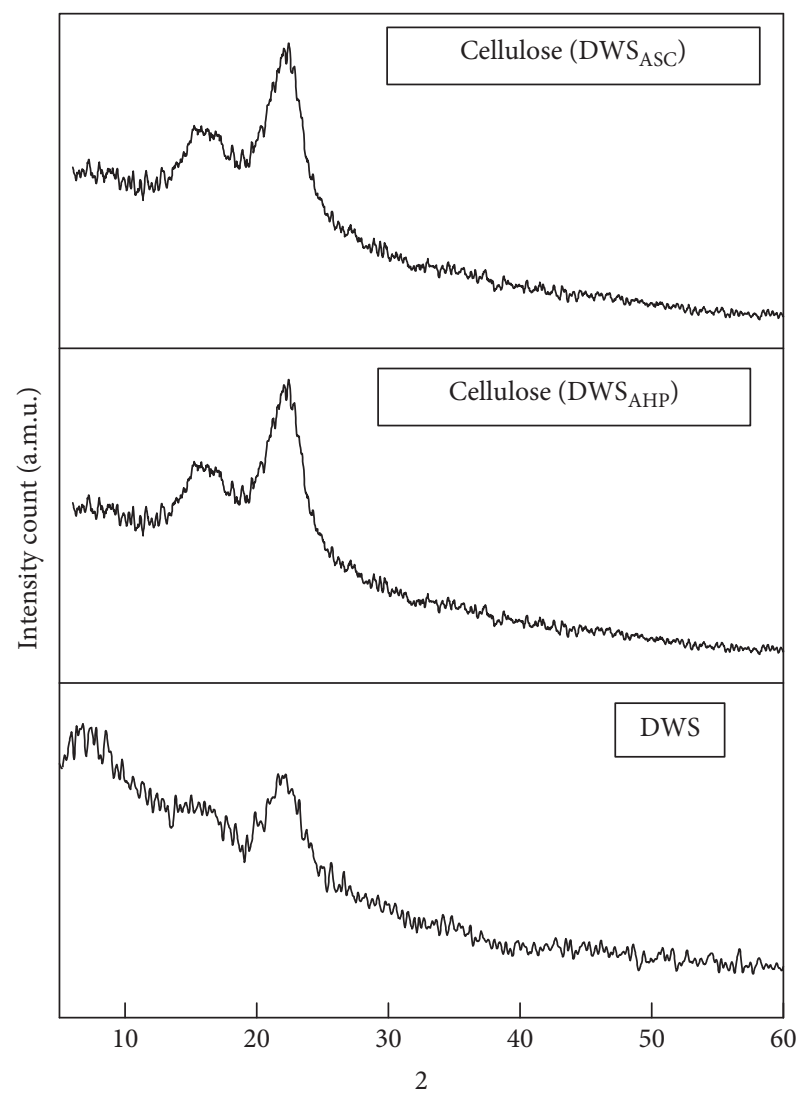

Figure 2: X-ray diffractogram of DWS, cellulose $\left(\mathrm{DWS}_{\mathrm{ASC}}\right)$, and cellulose $\left(\mathrm{DWS}_{\mathrm{AHP}}\right)$.

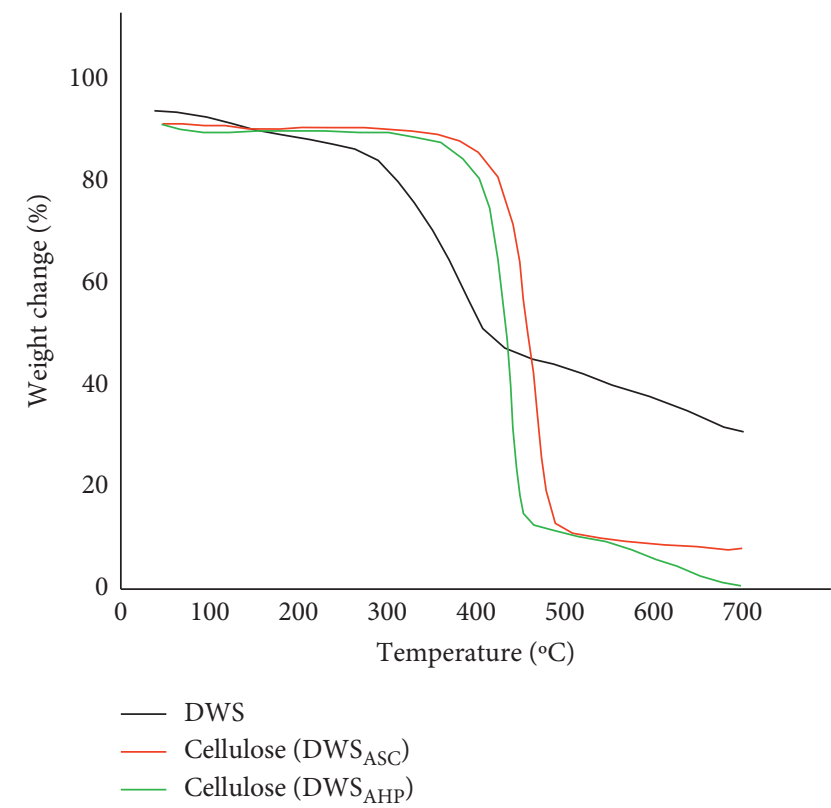

FIgURE 3: TGA thermograph of DWS, cellulose $\left(\mathrm{DWS}_{\mathrm{AHP}}\right)$, and cellulose $\left(\mathrm{DWS}_{\mathrm{ASC}}\right)$.

the removal of some components, while cellulose obtained after acidified sodium chlorite treatment is straight fiber connected with each other forming a regular shape. After the following treatments, it is evident that chemicals had 


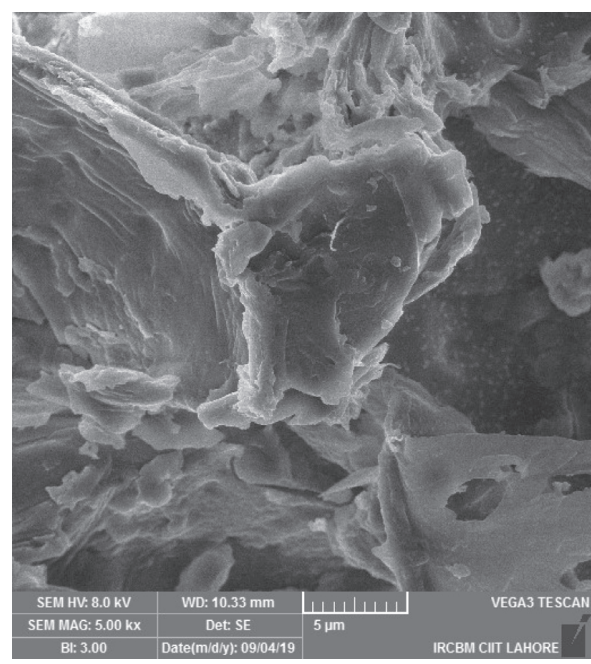

(a)

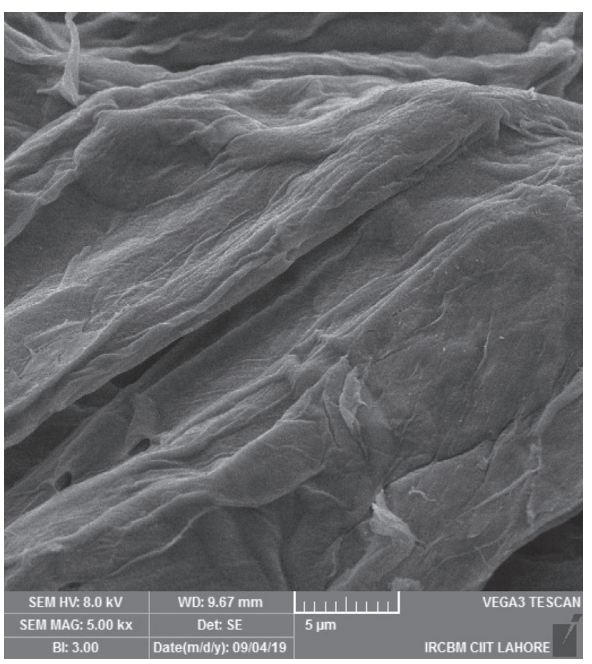

(b)

FIGURE 4: SEM image of (a) cellulose after $\mathrm{DWS}_{\mathrm{AHP}}$ and (b) cellulose after DWS $\mathrm{ASC}_{\text {. }}$

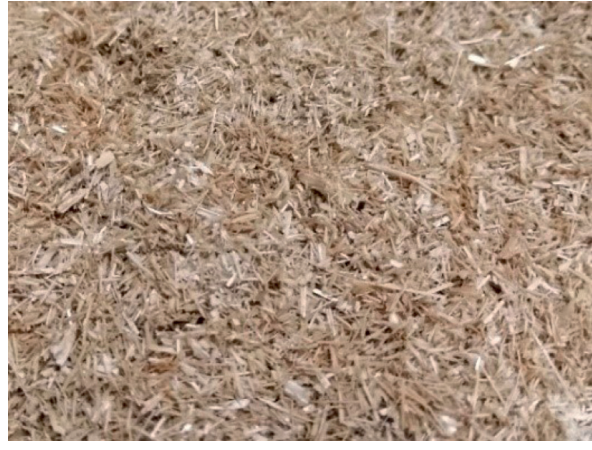

(a)

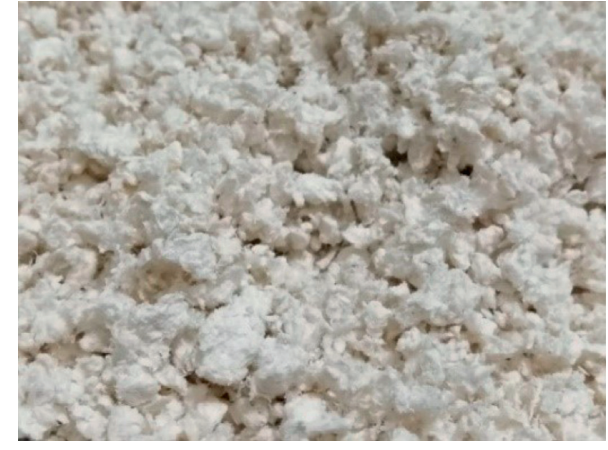

(b)

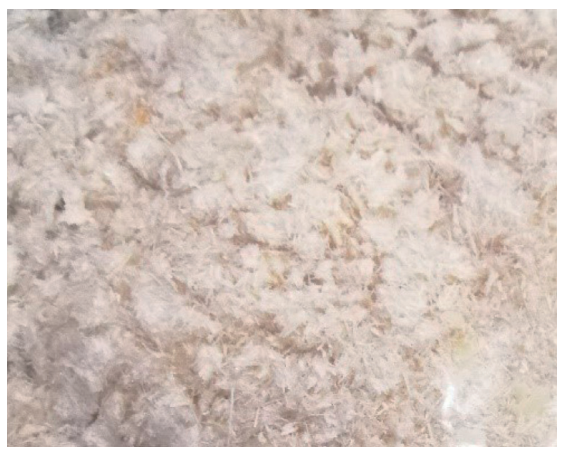

(c)

FIGURE 5: Physical representation of DWS (a), DWS $\mathrm{AHP}(\mathrm{b})$, and $\mathrm{DWS}_{\mathrm{ASC}}$ (c).

significant effect on the morphology of wheat straw (DWS) as after the treatments, irregular shape, reduced volume, and diameter of the fibers can be observed in SEM images.

3.6. Physical Appearance. Physical appearance of DWS, $\mathrm{DWS}_{\mathrm{ASC}}$, and $\mathrm{DWS}_{\mathrm{AHP}}$ is shown in Figure 5. After the treatments (ASC and AHP), the DWS obtained was purely white in color which exhibited that the noncellulosic components (lignin and hemicellulose) were removed.

\section{Comparison}

While isolating cellulose using two different pretreatment methods, important differences were noticed as follows: 
(1) During isolation, time is an important factor. ASC treatment involves more steps as compared to AHP treatment, because of this ASC treatment takes more time

(2) AHP treatment required high temperature conditions $\left(121^{\circ} \mathrm{C}\right)$ while ASC treatment worked at $70-80^{\circ} \mathrm{C}$ temperature conditions.

(3) Yield of ASC treatment is high as compared to AHP treatment

(4) Cellulose obtained from ASC treated wheat straw shows a bit better thermal stability as compared to cellulose obtained from AHP treatment

(5) Cellulose obtained from both treatments (ASC and AHP) shows almost same crystallinity

(6) AHP treatment is more eco-friendly as compared to ASC treatment because of completely chlorine-free process

(7) AHP treated wheat straw shows irregular shape while the wheat straw treated with ASC shows regular shape of treated fibers.

\section{Conclusion}

In this study, cellulose was successfully isolated from wheat straw using two different treatments: acidified sodium chlorite and alkaline hydrogen peroxide. Followed by the treatments, the residues were characterized by FT-IR, which indicated that the obtained material was cellulose containing traces or very low amount of hemicellulose and lignin. SEM analysis showed irregular structure of cellulose fiber obtained after the treatment of alkaline hydrogen peroxide, while a more regular structure appeared after the treatment of dewaxed wheat straw with acidified sodium chlorite. XRD results showed that the crystallinity of cellulose was almost the same for both the isolation methods. Cellulose obtained using acidified sodium chlorite treatment $\left(310^{\circ} \mathrm{C}\right)$ showed better thermal stability as compared to the alkaline hydrogen peroxide method $\left(304^{\circ} \mathrm{C}\right)$. In terms of time and yield, acidified sodium chlorite treatment turned out to be more time consuming with high yield of $81.4 \%$. Alkaline hydrogen peroxide treatment took less time but produced comparatively less yield of $79 \%$. This alkaline hydrogen peroxide treatment is more eco-friendly, being totally chlorine free. However, sodium chlorite treatment turned to have the most attractive property.

\section{Data Availability}

The datasets generated during and/or analyzed during the current study are available from the corresponding author upon reasonable request.

\section{Conflicts of Interest}

The authors declare that there are no conflicts of interest regarding the publication of this paper.

\section{Acknowledgments}

The authors are thankful to COMSATS University Islamabad, Lahore Campus, for providing all the support.

\section{References}

[1] G. N. Juárez-Luna, E. Favela-Torres, I. R. Quevedo, and N. Batina, "Enzymatically assisted isolation of high-quality cellulose nanoparticles from water hyacinth stems," Carbohydrate Polymers, vol. 220, pp. 110-117, 2019.

[2] M.R. Sanjay, S. Siengchin, J. Parameswaranpillai, M. Jawaid, C. I. Pruncu, and A. Khan, "A comprehensive review of techniques for natural fibers as reinforcement in composites: preparation, processing and characterization," Carbohydrate polymers, vol. 207, pp. 108-121, 2019.

[3] U. Asghar, M. Irfan, M. Iram et al., "Effect of alkaline pretreatment on delignification of wheat straw," Natural Product Research, vol. 29, no. 2, pp. 125-131, 2015.

[4] A. K. Bharimalla, S. P. Deshmukh, N. Vigneshwaran, P. G. Patil, and V. Prasad, "Nanocellulose-polymer composites: novel materials for food packaging applications," in Polymers for Agri-Food Applications, pp. 553-599, Springer, Berlin, Germany, 2019.

[5] A. Dufresne, "Nanocellulose processing properties and potential applications," Current Forestry Reports, vol. 5, no. 2, pp. 76-89, 2019.

[6] M. M. de Souza Lima and R. Borsali, "Rodlike cellulose microcrystals: structure, properties, and applications," Macromolecular Rapid Communications, vol. 25, no. 7, pp. 771787, 2004.

[7] M. T. Postek, R. J. Moon, A. W. Rudie, and M. A. Bilodeau, Production and Applications of Cellulose Nanomaterials, Tappi Press, Peachtree Corners, GA, USA, 2013.

[8] G. Siqueira, J. Bras, and A. Dufresne, "Cellulosic bionanocomposites: a review of preparation, properties and applications," Polymers, vol. 2, no. 4, pp. 728-765, 2010.

[9] M. A. Hubbe, O. J. Rojas, L. A. Lucia, and M. Sain, "Cellulosic nanocomposites: a review," BioResources, vol. 3, no. 3, pp. 929-980, 2008.

[10] N. Lin, J. Huang, and A. Dufresne, "Preparation, properties and applications of polysaccharide nanocrystals in advanced functional nanomaterials: a review," Nanoscale, vol. 4, no. 11, pp. 3274-3294, 2012.

[11] R. J. Moon, A. Martini, J. Nairn, J. Simonsen, and J. Youngblood, "Cellulose nanomaterials review: structure, properties and nanocomposites," Chemical Society Reviews, vol. 40, no. 7, pp. 3941-3994, 2011.

[12] A. Kaushik, M. Singh, and G. Verma, "Green nanocomposites based on thermoplastic starch and steam exploded cellulose nanofibrils from wheat straw," Carbohydrate Polymers, vol. 82, no. 2, pp. 337-345, 2010.

[13] P. Luo and Z. Liu, "Effect of sulphate acid calalyzed ethanol cooking on enzymatic hydrolysis of wheat straw," in Proceedings of the 2010 4th International Conference on Bioinformatics and Biomedical Engineering, IEEE, Chengdu, China, June 2010.

[14] A. Tozluoğlu, Ö. Özyürek, Y. Çöpür, and H. Özdemir, "Integrated production of biofilm, bioethanol, and papermaking pulp from wheat straw," BioResources, vol. 10, no. 4, pp. 7834-7853, 2015.

[15] S. B. Halvarsson, H. Edlund, and M. Norgren, "Wheat straw as raw material for manufacture of straw MDF," BioResources, vol. 5, no. 2, pp. 1215-1231, 2010. 
[16] A. Alemdar and M. Sain, "Isolation and characterization of nanofibers from agricultural residues-wheat straw and soy hulls," Bioresource Technology, vol. 99, no. 6, pp. 1664-1671, 2008.

[17] M. S. Nazir, B. A. Wahjoedi, A. W. Yussof, and M. A. Abdullah, "Eco-friendly extraction and characterization of cellulose from oil palm empty fruit bunches," BioResources, vol. 8 , no. 2, pp. 2161-2172, 2013.

[18] T. Kondo, "The assignment of IR absorption bands due to free hydroxyl groups in cellulose," Cellulose, vol. 4, no. 4, pp. 281-292, 1997.

[19] N. Johar, I. Ahmad, and A. Dufresne, "Extraction, preparation and characterization of cellulose fibres and nanocrystals from rice husk," Industrial Crops and Products, vol. 37, no. 1, pp. 93-99, 2012.

[20] R. M. Sheltami, I. Abdullah, I. Ahmad, A. Dufresne, and H. Kargarzadeh, "Extraction of cellulose nanocrystals from mengkuang leaves (Pandanus tectorius)," Carbohydrate Polymers, vol. 88, no. 2, pp. 772-779, 2012.

[21] A. Kaushik and M. Singh, "Isolation and characterization of cellulose nanofibrils from wheat straw using steam explosion coupled with high shear homogenization," Carbohydrate Research, vol. 346, no. 1, pp. 76-85, 2011.

[22] M. Nuruddin, A. Tcherbi-Narteh, M. Hosur et al., "Cellulose microfibrils extracted from wheat straw: a novel approach," in Proceedings of the 45th ISTC, Witchita, KA, USA, October 2013. 